\section{Allergy and hematological malignancies risk: A possible implication of Immunoglobulin $E$, TNF- $\alpha$ and Interleukin 10}

\author{
Reham M El Shabrawy ${ }^{1}$, Ahmed A Al Nagar ${ }^{2}$, Mariam \\ $M$ Amin $^{3}$
}

\author{
${ }^{1}$ Medical Microbiology \& Immunology Department, Faculty of \\ Medicine, Zagazig University, Zagazig, Egypt. \\ ${ }^{2}$ Medical Oncology Department, Faculty of Medicine, Zagazig \\ University, Zagazig, Egypt. \\ ${ }^{3}$ Internal Medicine, Allergy \& Clinical Immunology Department, \\ Faculty of Medicine, Ain Shams University, Cairo, Egypt.
}

The Egyptian Journal of Immunology Volume 28 (3), 2021: 102-113 www.Ejimmunology.org
Corresponding author: Mariam Maged Amin, Internal Medicine, Allergy \& Clinical Immunology Department, Faculty of Medicine, Ain Shams University, Egypt. Email: mariammaged@med.asu.edu.eg.

\begin{abstract}
AllergoOncology is a current focus of scientific interest. A possible link between allergies and hematologic malignancies (HMs) existed, but the results are controversial. While some studies concluded that allergy is a risk factor for HMs, others consider allergy a protective factor. We aimed to investigate the frequency of allergic disorders among individuals with hematological malignancies versus hematological malignancies free individuals and to detect the possible implication of serum level of Immunoglobulin (Ig) E, interleukin (IL)-10 and tumor necrosis factor (TNF) $\alpha .75$ patients with HMs and 75 healthy controls were enrolled. Diagnosis of allergy was made by history, clinical examination, and skin prick testing (SPT), while measurements of serum total IgE, IL 10 and TNF $\alpha$ were done by ELISA. Allergy was diagnosed in $6.7 \%$ of the patients and $42.7 \%$ of the healthy controls $(P<0.001)$. There was a statistically significant decrease in serum total IgE and TNF- $\alpha$ and in patients than controls $(P=0.002,<0.001)$, respectively. In contrast, IL-10 showed no significant differences between the two groups. In conclusion, allergic disorders are less frequent in patients with HMs than healthy controls. Lack of allergic conditions, low serum total IgE and TNF $\alpha$ may be independent risk factors for hematological malignancies.
\end{abstract}

Keywords: Allergy, hematological malignancies, TNF- $\alpha$, Ig E, IL-10

Date received: 23 January 2021; accepted: 22 April 2021

\section{Introduction}

Hematological malignancies (HMs) represent $6.5 \%$ of all malignancies worldwide, in which $\mathrm{NHL}$ represented $2.7 \%$, leukemia accounted for $2.5 \%$, and multiple myeloma (MM) represented $0.8 \%$, while $\mathrm{HL}$ represented $0.5 \%$. HMS are a heterogeneous group of diseases resulting from malignant transformation of cells from the bone marrow or lymphatic system. ${ }^{1}$ The relation between Cancer and Allergy is controversial.
Previous research proposed some mechanisms which might either decrease or increase the risk of malignancy. Immunologic surveillance and antineoplastic defense may eliminate malignant cells of a developing tumor at an early stage. Existing research indicates that dysregulation of the immune system, found in allergy, can affect tumor survival, suggesting that cancer in such patients may differ from those who do not suffer. On the contrary, chronic immune 
stimulation could boost malignancy. However still, these theories are inconsistent. ${ }^{1}$

Inflammation and resulted cytokines play a pathological role in the induction and progress of hematological malignancies. ${ }^{2}$ Several key mediators in allergy may affect the development of hematological cancers as immunoglobulin (Ig) $\mathrm{E}$, which have an essential role in allergy and also share in immune surveillance and host defense. IgE receptors FcER1 are present on mast cells, eosinophilis, DCs, macrophages and basophils. IgE-FcER1 interaction result in cell activation and degranulation, therefore a potent inflammatory reaction is produced.

Tumour necrosis factor-alpha (TNF $\alpha$ ), a pleiotropic cytokine, is also thought to play a significant role in the pathogenesis of inflammatory diseases, as an allergy. TNF $\alpha$ production occurs at the early stage of allergen sensitization and then promotes the inflammatory cascade in the effector phase of allergic reactions. ${ }^{4}$ Meanwhile, the role of TNF $\alpha$ in cancer is controversial; under certain circumstances, it induces cell apoptosis, and it may cause cell proliferation. ${ }^{1}$ The effect of TNF $\alpha$ largely relies on the receptor it binds. If soluble TNF $\alpha$ binds the tumor necrosis factor receptor 1 (TNFR1), the interaction will induce apoptosis, while if the molecule interacts with tumor necrosis factor receptor 2 (TNFR2), this will stimulate cell survival. $^{2}$

Interleukin 10 (IL-10) is a known crucial pleiotropic cytokine that can promote and curb Th2-dependent allergic responses. Simultaneously, IL-10 is an essential immunosuppressive cytokine that is frequently elevated in the tumor microenvironment. ${ }^{5}$

In this study, we tried to uncover a possible relation between allergy and HMs by evaluating the frequency of allergic disorders among individuals with hematological malignancies and compare it with the frequency in healthy individuals. Additionally, we investigated a probable immunopathogenic link by comparing serum level of some critical mediators that play a crucial role in allergy and HMs, mainly IgE, IL10 and TNF $\alpha$ between the studied groups.

\section{Patients and Methods}

\section{Study participants}

This cross-sectional study included 75 patients with different hematological malignancies and 75 healthy controls, during the period from November 2018 to July 2019. Diagnosis of patients was carried out according to the National Comprehensive Cancer Network (NCCN) guidelines for NCCN Guidelines for Detection, Prevention, \& Risk Reduction. ${ }_{-}^{6}$ The study included patients with Acute lymphocytic leukemia, Acute myeloid leukemia, Chronic Lymphocytic Leukemia, Chronic myeloid leukemia, Hodgkin Lymphoma, leukemia type M3, Multiple myeloma, Non-Hodgkin lymphoma and plasma cell dyscrasia.

Patients treated from cancer or receiving immunotherapy or anti-IgE (Omalizumab), patients with any autoimmune diseases, solid tumors, end-organ failure, or any other causes of elevated serum IgE and participants refusing to sign a consent were excluded from the study. The study was reviewed and approved by the Faculty of Medicine's Institutional review board, Zagazig University, Egypt. All individuals included in the study signed informed consent.

\section{Study design}

All participants were subjected to a questionnaire on allergic symptomatology, triggering factors, associated atopic diseases, cancer risk factors, family history and medications with complete clinical examination. Diagnosis of allergic diseases was performed according to the international guidelines. Allergic rhinitis was diagnosed according to allergic rhinitis, and its impact on asthma (ARIA) guidelines, ${ }^{7}$ Global initiative for asthma (GINA) guidelines were followed for the diagnosis of Bronchial asthma. ${ }^{8}$ Diagnosis of Skin allergy was made according to the European Academy of Allergy and Clinical Immunology (EACCI) guidelines. ${ }^{9}$ Allergy investigations were carried out for all participants with a history suggestive of allergy, including skin prick test and specific serum IgE if needed. Serum total IgE, IL10 and TNF- $\alpha$ were measured for all participants. In addition to pulmonary function test in bronchial asthma cases and the required laboratory or 
radiological investigations for the underlying HMs. $^{9}$

\section{Skin prick test (SPT)}

It was performed according to the European Academy of Allergy and Clinical Immunology (EAACI). SPT to allergens was used to determine atopic status. Positive $(0.1 \%$ histamine in phosphate-buffered saline) and negative (physiologic saline) controls were used. A wheel size over $3 \mathrm{~mm}$ greater than the negative control after 15 minutes was considered a positive result. ${ }^{10}$

\section{Diagnosis of asthma.}

Asthma was diagnosed according to the Global Initiative for Asthma (GINA) guidelines; symptoms suggest asthma diagnosis include wheeze, shortness of breath, cough, and chest tightness. These symptoms often worse at night, vary in intensity over time, and triggered by viral infections, exercise and allergen exposure. Diagnosis is confirmed by spirometry when forced expiratory volume1 (FEV1) improved by $\geq 12 \%$ after inhalation of salbutamol. ${ }^{8,11}$

\section{Total serum IgE}

Total serum IgE was measured using a commercially available double-antibody sandwich enzyme-linked immunosorbent assay (ELISA). Kit specified to assay human serum (Bio check total IgE, South San Francisco). In principle, IgE in the serum binds to monoclonal antibody-Enzyme in a well, which is pre-coated with goat IgE monoclonal antibody. Standardized reference solutions $(0,10,50,400$ and $800 \mathrm{IU} / \mathrm{ml}$ ) were used. Patient's sera and standard solutions were added to wells and allowed to react for $30 \mathrm{~min}$ at room temperature. Wells were washed, and to each well, antibodies labelled with an enzyme (Streptavidin-HRP) were added and reacted for $30 \mathrm{~min}$ at room temperature. After washing, the chromogen solution of tetramethylbenzidine (TMB) was added and allowed to react for 20 $\min$ at $37^{\circ} \mathrm{c}$. 3- Finally, the stop solution was added, and the optical density was measured at $450 \mathrm{~nm}$ wavelength (Biotek ELISA plate reader) within $10 \mathrm{~min}$. To calculate sample concentrations, a standard curve was drawn by plotting the standard solutions' concentration vs OD. The minimum detectable level was 5 $\mathrm{IU} / \mathrm{ml}^{12}$

\section{Serum IL-10}

IL-10 measuring was done using an ELISA kit specified to human serum assay (Shanghai Sunred Biological Technology, China). Test principle: IL-10 in the serum binds to monoclonal antibody Enzyme well, which is precoated with IL-10 monoclonal antibody. A standard solution of $3200 \mathrm{pg} / \mathrm{ml}$, was serially diluted to concentrations of $1600 \mathrm{pg} / \mathrm{ml}, 800$ $\mathrm{pg} / \mathrm{ml}, 400 \mathrm{pg} / \mathrm{ml}, 200 \mathrm{pg} / \mathrm{ml}$ and $100 \mathrm{pg} / \mathrm{ml}$. Patient's sera and standard solutions were added to wells. To each well, antibodies labelled with enzymes (Streptavidin-HRP) were added and then left to react for $60 \mathrm{~min}$ at $37^{\circ} \mathrm{C}$. 3- After washing five times with the washing solution, the chromogen solutions $A$ and $B$ were added and reacted for $10 \mathrm{~min}$ at $37^{\circ} \mathrm{C}$. Finally, the stop solution was added, and the optical density was measured at $450 \mathrm{~nm}$ wavelength within $10 \mathrm{~min}$. Sample concentration was determined using a standard curve. The sensitivity of the kit was $9.012 \mathrm{pg} / \mathrm{ml}$, assay range $10-3000 \mathrm{pg} / \mathrm{ml}^{13}$

\section{Serum TNF- $\alpha$}

TNF- $\alpha$ was measured by an ELISA kit specified to assay human serum (Wuhan Fine Biotech Co., Ltd, China). In principle, TNF- $\alpha$ in the serum binds to monoclonal antibody- Enzyme in a well which is pre-coated with TNF- $\alpha$ monoclonal antibody. A standard solution of $1000 \mathrm{pg} / \mathrm{ml}$, was serially diluted to produce concentrations of $500 \mathrm{pg} / \mathrm{ml}, 250 \mathrm{pg} / \mathrm{ml}, 125 \mathrm{pg} / \mathrm{ml}, 62.5 \mathrm{pg} / \mathrm{ml}$ and $31.25 \mathrm{pg} / \mathrm{ml}$. Patient's sera and standards were added to wells. To each well, anti-TNF- $\alpha$ antibodies labelled with enzymes (StreptavidinHRP) were added and left to react for $60 \mathrm{~min}$ at $37{ }^{\circ} \mathrm{C}$. After washing five times, the chromogen was added and allowed to react for $10 \mathrm{~min}$ at $37^{\circ} \mathrm{C}$. A stop solution was added, and the optical density was measured at $450 \mathrm{~nm}$ wavelength within $10 \mathrm{~m}$. Sample concentration was determined using the constructed standard curve. The assay range was: $15.625-1000 \mathrm{pg} / \mathrm{ml}$; and sensitivity: $9.375 \mathrm{pg} / \mathrm{ml}^{14}$ 


\section{Statistical methodology}

The collected data were computerized and statistically analyzed using the SPSS program (Statistical Package for Social Science) version 25.0. Qualitative data were shown as frequencies and percentages. A Chi-square test was used to calculate the difference between qualitative variables. Quantitative data were shown as mean \pm SD (Standard deviation), median and range. Mann Whitney test \& Kruskal Wallis test was used to calculate the difference between quantitative variables. The odds ratio quantifies the strength between two events. Logistic regression analysis was used to predict the risk of developing HMs based on different variables (age, sex, presence of allergy, Family history of allergy, low total serum IgE, low serum IL-10, and low serum TNF $\alpha$ ). The analysis is used to ensure that each factor can independently affect the development of HMs irrespective of other factors. Wald statistic regression is part of the logistic regression; it is analogous to the $t$-test in linear regression and used to assess coefficients' significance. To correct the logistic regression to be valid for the general population, the $\beta$ parameter was calculated. ${ }^{15}$ P-value of $<0.05$ was considered significant, with a $95 \%$ confidence interval (Cl) and a P-value of $<0.01$ indicates highly significant results.

\section{Results}

Demographic and clinical characteristics of the studied groups

There was no statistically significant difference regarding gender or age between the two studied groups. The most common malignancies detected in patients with HMs were AML (23), followed by ALL (17) (table 1). Regarding the frequency of allergic disorders, only five patients $(6.7 \%)$ were diagnosed to have allergy in the patients with HMs compared to 32 patients $32(42.7 \%)$ in the healthy controls with high statistical significance $(P=<0.001)$.

Table 1. Demographic and clinical characteristics of the studied groups.

\begin{tabular}{|c|c|c|c|c|}
\hline & Variable & $\begin{array}{c}\text { HMs patients } \\
n=75\end{array}$ & $\begin{array}{c}\text { Controls } \\
n=75\end{array}$ & ${ }^{*} P$-value \\
\hline \multirow{2}{*}{ Age (years) } & Mean \pm SD & $47.61 \pm 14.8$ & $46.51 \pm 13.8$ & \multirow{2}{*}{ NS } \\
\hline & Range & $17-73$ & $17-68$ & \\
\hline \multirow{2}{*}{ Gender } & Male & 35 (46.7\%) & $32(42.7 \%)$ & \multirow{2}{*}{ NS } \\
\hline & Female & 40 (53.3\%) & 43 (57.3\%) & \\
\hline \multirow{4}{*}{$\begin{array}{l}\text { Allergy no } \\
\text { (percentage) }\end{array}$} & Allergic rhinitis & $2(2.7 \%)$ & $20(18.7 \%)$ & $<0.001 * *$ \\
\hline & Bronchial asthma & $3(4.0 \%)$ & $12(10.7 \%)$ & $0.002 * *$ \\
\hline & Skin allergy & 0 & $10(4 \%)$ & NS \\
\hline & Total & $5(6.7 \%)$ & 32 (42.7\%) & $<0.001 * *$ \\
\hline \multirow{9}{*}{ Type of cancer } & ALL & $17(22.6)$ & \multirow{9}{*}{ ND } & \multirow{9}{*}{ ND } \\
\hline & AML & $23(30.6)$ & & \\
\hline & CLL & $11(14.6)$ & & \\
\hline & $\mathrm{CML}$ & $4(5.4)$ & & \\
\hline & $\mathrm{HL}$ & $12(16)$ & & \\
\hline & M3 & $2(2.7)$ & & \\
\hline & MM & $2(2.7)$ & & \\
\hline & $\mathrm{NHL}$ & $2(2.7)$ & & \\
\hline & PCD & $2(2.7)$ & & \\
\hline
\end{tabular}

MW: Mann Whitney, $\chi 2$ : Chi-square *: $P>0.5$ is not significant (NS), ND: Not done. ALL: Acute lymphocytic leukemia, AML: Acute myeloid leukemia, CLL; Chronic Lymphocytic Leukemia, CML: Chronic myeloid leukemia, HL: Hodgkin Lymphoma, M3: Leukemia M3 type, MM : Multiple myeloma, NHL: Non Hodgkin Lymphoma, PCD: Plasma cell dyscrasia 
Results of skin prick test:

For HMs patients, five patients were allergic to mite (6.6\%), three to cockroach (4\%), three for ragweeds (4\%), two for feathers (2.6\%), two $(2.6 \%)$ for timothy grass and one patient (1.3\%) was allergic to cat dander and epithelium.

For healthy controls, Mites were the most commonly (14(18.6\%) individuals), then timothy grass (10 (13.3\%) individuals), Sunflower8
(10.8\%), followed by feather and Chenopodium (6 individuals each (8\%)), Penicillium 5 (2.6\%), Cockroach 4 (5.3\%), Rye (5.3\%), and two patients (2.6\%) for Cladosporium, cat, and dog epithelium and dander. Due to the limited number of allergic patients in the patients with $\mathrm{HMs}$, statistical analysis of the skin prick test results was not done (figure 1 ).

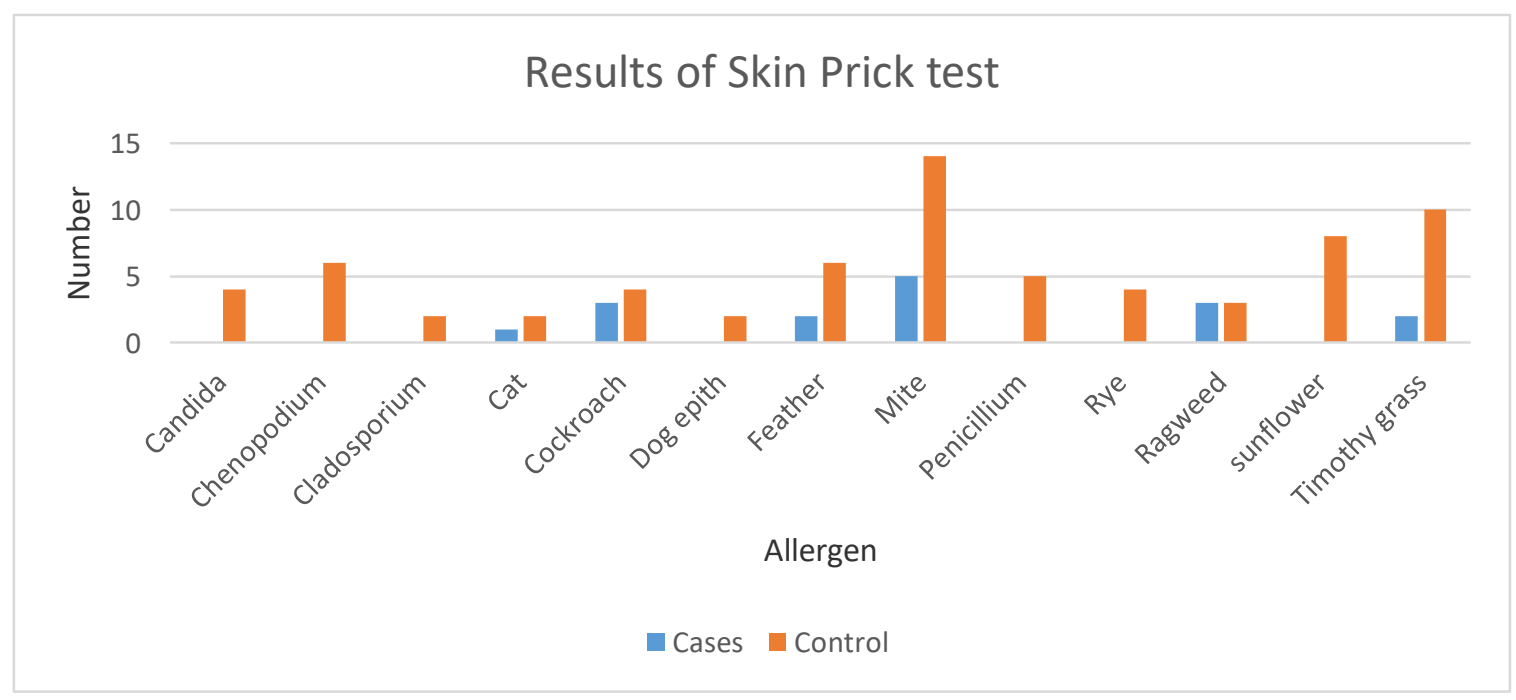

Figure 1. Results of skin prick test.

Serum level of IgE, IL-10 \& TNF- $\alpha$ in allergic and non-allergic participants among both cases and healthy controls

When comparing the levels of IgE and TNF- $\alpha$ in allergic and non-allergic individuals among patients with HMs groups, there were statistically significant increase in IgE and TNF- $\alpha$ in the allergic individuals $(P=0.04)$ and (0.03) respectively. Regarding the levels of IgE, and TNF- $\alpha$ between allergic and non-allergic individuals included in the control group, there were statistically significant increase in IgE and TNF- $\alpha$ in allergic patients $(P=0.04)$ and $(<0.001)$ respectively. However, IL-10 showed no statistically significant differences between allergic and nonallergic patients in both groups ( $P=0.33, P=0.88)$.

Serum IgE, IL-10 \& TNF- $\alpha$ between patients and healthy controls

When comparing serum levels of IgE, IL-10 \& TNF- $\alpha$ between HMs patients and healthy controls, the level of serum IgE was statistically higher in patients than in healthy controls $(P=0.002)$. TNF- $\alpha$ the serum level in healthy control was significantly higher than in patients with HMs $(P<0.001)$. However, IL-10 showed no statistically significant differences between the two studied groups ( $P=0.13$ ) (table 2 ). 
Table 2. Comparison of serum total immunoglobulin (Ig) E, interleukin -10 \& tumor necrosis factor $\alpha$ between patients and controls.

\begin{tabular}{|c|c|c|c|c|}
\hline & & Median (Range) & Mean \pm SD & ${ }^{*} P$-value (MW) \\
\hline \multirow{2}{*}{$\lg E(\mathrm{lu} / \mathrm{ml})$} & HMS patients 75 & $16(1-46)$ & $19.32 \pm 13.0$ & \multirow{2}{*}{0.002} \\
\hline & Controls 75 & 25 (4.4- 290) & $57.93 \pm 73.9$ & \\
\hline \multirow{2}{*}{ IL-10 (pg/ml) } & HMs patients 75 & 1109 (446- 3179) & $1109 \pm 441$ & \multirow{2}{*}{ NS } \\
\hline & Controls 75 & $1288(77.5-3477)$ & $1252 \pm 734$ & \\
\hline \multirow{2}{*}{ TNF- $\alpha$ (ng/ml) } & HMS patients 75 & $175.6(22.6-729.3)$ & $191 \pm 171$ & \multirow{2}{*}{$<0.001$} \\
\hline & Controls 75 & 324 (111.3- 2051) & $558 \pm 602$ & \\
\hline
\end{tabular}

IgE: Immunoglobulin E, IL-10: interleukin 10; TNF- $\alpha$ : Tumor necrosis factor $\alpha$; SD: standard deviation, MW: Mann Whitney,

$*: P>0.5$ is not significant (NS),

Relationship between type of cancer and serum total IgE, IL-10 \& TNF among cases group:

$A M L$ and ALL showed a significant increase in the level of IgE $(P=0.03)$ and TNF- $\alpha(0.04)$ compared with other types of hematological malignancies. Nevertheless, there was no significant difference between different types of malignancies regarding serum IL-10 level (table 3).

Table 3. Relation between type of cancer and serum total immunoglobulin E, interleukin -10 \& tumor necrosis factor $\alpha$ among patients with different hematological disorders.

\begin{tabular}{|c|c|c|c|c|c|c|}
\hline & $\begin{array}{l}\text { Hematological } \\
\text { malignancy }\end{array}$ & $\mathrm{N}$ & Mean \pm SD & Median & Range & $\begin{array}{l}{ }^{* P} \text { value } \\
\text { (KW) }\end{array}$ \\
\hline \multirow{6}{*}{$\operatorname{lgE}(\mathrm{lu} / \mathrm{ml})$} & ALL & 17 & $21.28 \pm 9.67$ & $23^{*}$ & $6.40-37.00$ & \multirow{6}{*}{0.03} \\
\hline & AML & 23 & $21.52 \pm 16.98$ & $22 *$ & $1.50-46.00$ & \\
\hline & CLL & 11 & $13.49 \pm 10.78$ & 11.7 & $1.00-28.00$ & \\
\hline & CML & 4 & $9.30 \pm 4.27$ & 16.3 & $5.60-13.00$ & \\
\hline & Lymphoma & 12 & $13.85 \pm 7.29$ & 14.75 & $1.50-23.40$ & \\
\hline & Others & 8 & $30.02 \pm 9.62$ & $27 *$ & $21.10-45.00$ & \\
\hline \multirow{6}{*}{ IL-10 (pg/ml) } & ALL & 17 & $1289.6 \pm 775.04$ & 1134 & $548.0-3179.0$ & \multirow{6}{*}{ NS } \\
\hline & AML & 23 & $1006.6 \pm 270.57$ & 1067 & $446.2-1345.0$ & \\
\hline & $\mathrm{CLL}$ & 11 & $1123.3 \pm 147.48$ & 1156 & $905.0-1321.0$ & \\
\hline & $\mathrm{CML}$ & 4 & $1209.0 \pm 115.47$ & 1209 & $1109.0-1309.0$ & \\
\hline & Lymphoma & 12 & $911.54 \pm 223.99$ & 984 & $492.0-1189.0$ & \\
\hline & Others & 8 & $1253.9 \pm 365.13$ & 1350 & $696.0-1624.0$ & \\
\hline \multirow{6}{*}{ TNFa (ng/ml) } & ALL & 17 & $211.81 \pm 135.69$ & $175.6^{*}$ & 111.3- 729.3 & \multirow{6}{*}{0.04} \\
\hline & AML & 23 & $199.17 \pm 21.60$ & $167.8 *$ & 22.6- 729.3 & \\
\hline & $\mathrm{CLL}$ & 11 & $112.45 \pm 65.60$ & 125 & $22.6-213.0$ & \\
\hline & $\mathrm{CML}$ & 4 & $141.65 \pm 76.60$ & 143 & 54.6- 213.0 & \\
\hline & Lymphoma & 12 & $140.60 \pm 66.64$ & 135.6 & $22.6-213.0$ & \\
\hline & Others & 8 & $312.27 \pm 262.12$ & $193 *$ & 54.6- 729.3 & \\
\hline
\end{tabular}

ALL: Acute lymphocytic leukemia; AML: Acute myeloid leukemia; CLL: Chronic Lymphocytic Leukemia; CML: Chronic myeloid leukemia; KW: Kruskal Wallis. N: number. *: $P>0.5$ is not significant (NS). 
Logistic regression analysis for the relationship between the developments of hematological malignancies adjusted for the other possible confounding factors

Logistic regression was used to assess the effect of all studied factors on the development of Hematological malignancies. According to this type of analysis, each variable is analyzed independently to other factors using the Wald coefficient; then, the values were corrected to be applicable for the entire population (as the current study is a case-control study) using the $\beta$ parameter. Logistic regression analysis showed that factors that can significantly protect against the development of HMs are the presence of an allergy, the presence of a family history of allergy, High serum IgE level, and high TNF $\alpha$ level. On the other hand, age, gender and serum IL-10 did not significantly affect the development of HMs.

Table 4. Logistic regression analysis for the relation between the developments of hematological malignancies adjusted for the other possible confounding factors.

\begin{tabular}{lccccc}
\hline Independent factors & $\beta$ & SE & Wald & OR $(95 \% \mathrm{Cl})$ & ${ }^{*} P$-value \\
\hline Age & 0.53 & 0.27 & 3 & $1.69(0.81-2.99)$ & NS \\
\hline Gender & 0.70 & 0.36 & 2.7 & $1.03(0.68-3.12)$ & NS \\
\hline Allergy & -1.33 & 0.38 & 12.18 & $0.86(0.54-0.92)$ & $<0.001$ \\
\hline Family history & -1.87 & 0.51 & 13.39 & $0.69(0.53-0.85)$ & 0.03 \\
\hline High serum IgE & 1.16 & 0.52 & 4.82 & $3.19(1.13-8.98)$ & 0.02 \\
\hline Serum IL-10 & 0.75 & 0.41 & 3.1 & $2.01(0.85-4.65)$ & NS \\
\hline High TNF $\alpha$ & 2.10 & 0.61 & 20.81 & $7.35(3.28-16.5)$ & $<0.001$
\end{tabular}

IgE: Immunoglobulin E, IL-10: interleukin 10; TNF- $\alpha$ : Tumor necrosis factor $\alpha$; ${ }^{* *}$ : Highly significant. SE: Standard error, $\beta$ : $\beta$ parameter, Wald: Wald statistic coefficient, OR: odds ratio, $\mathrm{Cl}$ : confidence interval. *: $P>0.5$ is not significant (NS).

\section{Discussion}

Conflicting hypotheses have been proposed to determine the relationship between atopy and cancer, the immune surveillance hypothesis and the antigenic stimulation hypothesis. The former advocates that allergic conditions may be protective against the development of HMs, which was also supported by our study, whereas the latter proposes an increased risk. The immune surveillance hypothesis suggests that the immune system recognizes malignant cells' antigens as foreign and reacts against them, preventing cancers' development. Hence, immunocompromised persons have a higher incidence of some malignancies. On the other hand, chronic stimulation of the immune system by allergens may increase the risk of carcinogenesis due to an increase in the probability of genetic errors, as pro-oncogenic mutations. ${ }^{16}$
Firstly, we aimed to evaluate the frequency of the previous allergy among individuals with hematological malignancies. Our study included 75 patients with different hematological malignancies compared to 75 healthy controls. We observed a marked increase in allergy frequency in the healthy controls compared to patients with HMs with a highly statistically significant difference. This agrees with a metanalysis which included 148 papers published from 1955 through 2006 and revealed that allergy protects against cancer with multiple myeloma (MM), non-Hodgkin's lymphoma (NHL), and myelocytic leukemia being sporadic in allergic patients. ${ }^{17}$

However, Shadman et al., when examined the association between allergies and HMs in 66,212 participants, found an association between airborne allergy and increased risk of HMs. This association was strongest between grass and tree pollen and mature B-cell lymphomas. ${ }^{18}$ Besides, other studies also found 
an association between the presence of an allergic condition and an increase in the risk of $\mathrm{NHL}{ }^{19}$ Hodgkin Lymphoma $(\mathrm{HL})^{20,21}$ and lymphoplasmacytic lymphoma. ${ }^{22}$ In another Swedish study, leukemia was found to be higher in patients with a history of hives (RR $=2.1[1.0$ 4.5]). ${ }^{23}$

The immune-surveillance hypothesis explains how allergy can be a protective factor against HMs, which suggest that allergic diseases enhance the immune system's ability to detect and eliminate neoplastic cells, thus preventing cancers. There is bone marrow involvement termed as the 'reflex" nature of the allergic disease, which can be observed in atopy. This leads to epigenetic reprogramming, which increases antigen-presenting cell activity. ${ }^{24}$ Another possible explanation is the adrenal hypothesis, which indicates that infections induce changes in the hypothalamus-pituitaryadrenal axis with an elevation in plasmatic cortisol, eliminating leukemic and preleukemic cells. The same occurs in allergic conditions because of corticosteroids, which can protect against the development of malignancies. ${ }^{25} \mathrm{~A}$ less likely cause is histamine's anti-tumor activity, as it protects natural killer cells and $T$ cells against oxygen radical-induced damage and death by suppressing oxygen radical formation and adjusts lymphocyte activation by cytokines. ${ }^{26}$

Various clinical trials in $\mathrm{HMs}$ have demonstrated that combined immunotherapy and histamine dihydrochloride had improved treatment outcome, ${ }^{27}$ supporting histamine and other mediators of mast cells released in allergy tumour immune-regulating properties. $^{28}$ Antihistamines found to pose immunesuppressive or regulatory properties, including inhibition of antigen-specific and mitogeninduced lymphocyte proliferation ${ }^{29}$ and the induction of potent reduction of the activities of the active transcription factors followed by apoptosis and cell death. ${ }^{30}$

In this study, the small number of patients suffering from allergy in patients with HMs limits the ability to analyze the relationship between specific allergen and specific HMs. Shadman and colleagues detected that an allergy history to the airborne allergens, specifically plants, grass, and trees, was associated with an increased risk of HMs. However, this association was not similar across all the subtypes of HMs; it was primarily found for mature B-cell neoplasms. ${ }^{18}$ Extensive research is required before the conclusion. Also, many variables must be considered, as the genetic makeup of the studied population, the endemicity of particular infection and other environmental factors, the duration of allergy and the degree of severity.

Our results detected significant elevation of serum total IgE levels in the allergic population compared with non-allergic patients. Additionally, IgE serum levels were significantly higher in the healthy controls than the patients with HMs, which assumes IgE's protective role. When comparing IgE's difference between different groups of HMs, AML, and CML showed significantly lower IgE levels.

In line with our study, another study that included 1021 cases of HMs found that serum total IgE levels were inversely associated with MM, B-cell NHL and chronic lymphocytic leukemia risk. They also demonstrated significantly lower pre-diagnostic total IgE levels (low: <20; intermediate: 20-100; high >100 $\mathrm{kU} / \mathrm{l}$ ) among CLL and MM cases compared with matched controls. ${ }^{3}$ Besides, other studies in the USA, Spain and Scandinavia have shown reduced serum total IgE levels among CLL and MM patients compared with healthy participants. ${ }^{31}$ However, in our study were lower in AML and CML. Another study in Spain reported a significant inverse association between serum total IgE and lymphoma risk overall, especially CLL risks, followed by MM. ${ }^{32}$ Nieters and coworkers observed another inverse relationship of serum total IgE levels with risk of $\mathrm{CLL}$ and $\mathrm{MM}^{3}{ }^{3}$

In this context, it is believed that elevated serum IgE associated with allergic diseases confer a protective role against malignancy; IgE causes rapid expulsion of pathogens, natural toxins, and carcinogenic antigens before they can trigger malignant development. IgE can bind receptor FceRI present on mast cells, eosinophils, DCs, macrophages, and basophils, which also infiltrate the tumor microenvironment resulting in cell activation, degranulation; and an inflammatory reaction produced, eliminating the tumor. ${ }^{17}$ However, 
this study's limitation is that serum total IgE levels were only measured at a single time point. It is known that CLL is often affected by progressive immunodeficiency during disease and often present hypo-gammaglobulinemia of unknown origin. ${ }^{33}$ Therefore, it is difficult to assess whether low IgE levels preceded the HMs or that low IgE levels occurred because of the immune deficiency associated with HMs. Additionally, the inverse association observed between HMs and allergy may reflect a suppressed immunologic response to allergens.

According to our results, the serum level of IL-10 showed no statistically significant difference in healthy controls than patients with HMs. Consequently, no difference was found concerning different types of HMs. IL-10 is an immunoregulatory cytokine mainly produced by $\mathrm{T}$ helper and $\mathrm{T}$ regulatory cells, ${ }^{34}$ which is considered an effective anti-inflammatory cytokine, suppressing macrophage/ $T$ cell cytokine expression and inhibiting their antigenpresenting function. ${ }^{35}$ However, $\mathrm{IL}-10$ is thought to play a pleiotropic role in immune stimulation and suppression in the tumor microenvironment. ${ }^{36}$

As an inflammatory modulatory cytokine, IL10 exert both anti-tumor and pro-tumor function. ${ }^{37} \mathrm{~A}$ high level of IL-10 was reported to correlate with poor survival of some cancer patients, ${ }^{34}$ while some other studies provided opposite results. ${ }^{39}$ Both human recombined IL10 and IL-10 antagonist have been launched for cancer therapy. ${ }^{40}$ Deep insights into the controversial roles of $\mathrm{IL}-10$ in cancer are needed to elucidate the potential use of IL-10 as a useful biomarker in the prognosis of cancer and as targeted therapy.

In this study, serum TNF- $\alpha$ shows a statistically higher level in allergic patients versus non-allergic patients in both groups. And it was significantly higher in the healthy controls versus the patients with HMs. According to these results, we suggest that patients with allergy have higher TNF- $\alpha$ than non-allergic patients and that TNF $\alpha$ may have a protective role against $\mathrm{HMs}$.

TNF- $\alpha$ plays a significant role in allergy pathogenesis and contributes to early and late allergy stages. ${ }^{41}$ Upon allergen exposure, TNF- $\alpha$ is produced by sensitized epithelial barriers and immune cells, promoting Th2 responses, ${ }^{42}$ resulting in high IL-4, IL-5, and IL-13, which further activate eosinophils basophils and mast cells. Additionally, TNF- $\alpha$ either induced or secreted by Th2 cells stimulate the production of antigen-specific lgE from $B$ cells. ${ }^{43}$

Besides, TNF- $\alpha$ is a significant effector with conflicting roles in hematologic malignancies, while it induces apoptosis in cancer cells sometimes, in certain circumstances, it stimulates cell proliferation. ${ }^{2}$ The serum level of TNF- $\alpha$ shows discrepancies in the different studies. A study has found that the mean level of TNF- $\alpha$ was significantly higher in AML than in healthy volunteers. ${ }^{44,45}$ And it was an adverse prognostic factor for survival and event-free survival. ${ }^{46}$ On the contrary, in another study, AML patients' analysis at diagnosis or during relapsed disease showed that TNF- $\alpha$ was significantly elevated in chronic leukemia and acute lymphoblastic leukemia but not in AML. ${ }^{47}$ The observed differences may be due to the presence of high inter-individual variations. TNF- $\alpha$ may act indirectly by rendering leukemic cell cytotoxic to residual normal hematopoietic cells, and thus it may contribute to hematopoiesis insufficiency. ${ }^{48}$

Logistic regression analysis in the current study detected that lack of previous allergic reactions, family history of allergy, low serum total IgE and serum TNF $\alpha$ could be independent risk factors for developing hematological malignancies. However, age, gender, and serum IL 10 are not independent risk factors for developing hematological malignancies. To the best of our knowledge, no other studies have studied regression analysis for serum total IgE, IL10 and TNF $\alpha$ concerning HMs. Only Shadman and colleagues detected an increased risk of HMs in women but not in men with a history of allergies to airborne allergens, predominantly plants, grass, or trees. ${ }^{18}$

In both allergy and cancer, antibodies may be beneficial or detrimental, depending on their epitope specificity. $^{49}$ In allergy, specific immunotherapy with allergens aims to induce antibodies that block but do not enhance the allergic reaction. Similarly, in targeting antigens overexpressed by malignant cells, growthinhibitory antibodies are preferred, whereas growth-stimulating specificities should be 
prevented. Therefore, it is essential to direct immune responses to allergen/antigen. ${ }^{46}$

Antibodies designed with Fc regions of the IgE class confer natural, long-lived immune surveillance through the tenacious engagement of high-affinity cognate Fc receptors on distinct, tumour-resident immune effector cells and through the ability to activate these cells under tumor-induced Th2-biased conditions. Several IgE-based active and passive immunotherapeutic approaches have been tried in different in vitro and in vivo models, suggesting IgE immunotherapies' potential in oncology. ${ }^{50,51}$ IgE antibodies directed against a tumor-associated antigen could trigger an immediate local effector cell response against the tumor cells. ${ }^{52}$ Engineered anti-tumor IgE antibodies have a high cytotoxic capacity. However, natural IgE has also been described in squamous cell carcinoma and pancreatic cancer, where its cytotoxic potential was also demonstrated..$^{53}$

In conclusion, there is an association between lack of previous allergy and hematological malignancies. Low levels of total serum IgE and TNFa may be independent risk factors. However, epidemiological studies on many patients with associated allergic conditions are required before any solid conclusion is drawn.

\section{Author Contributions}

Conception and design were RE, MM, and $A A$. Clinical diagnosis of hematological malignancies was the responsibility of AA. Laboratory investigations: RE. Diagnosis of allergy, allergy skin testing interpretation and manuscript writing: $\mathrm{MM}$ and RE. All authors shared in collecting data, data analysis and interpretation. were major contributors in writing the manuscript. All authors read and approved the final manuscript.

\section{Declaration of Conflicting Interests}

The author(s) declared no potential conflicts of interest with respect to the research, authorship, and/or publication of this article.

\section{Funding}

Authors denies receipt of any financial support for the research, authorship, or publication of this article:

\section{Ethical approval}

The study was reviewed and approved by the Faculty of Medicine's Institutional review board, Zagazig University, Egypt.

\section{Informed consent}

A signed consent form was obtained from each study participant.

\section{References}

1. Musolinoa C, Allegra A, Minciullob PL, et al. (2014) Allergy and risk of hematologic malignancies: Associations and Mechanisms. Leukemia Research; 8: 1137-44.

2. Tian T, Wang M, Ma D. (2014) TNF- $\alpha$, a good or bad factor in hematological diseases? Stem Cell Investig; 1:12.

3. Nieters A, Łuczyńska A, Becker S, et al. (2014) Prediagnostic immunoglobulin $E$ levels and risk of chronic lymphocytic leukemia, other lymphomas and multiple myeloma-results of the European Prospective Investigation into Cancer and Nutrition Carcinogenesis; 35(12): 2716-22.

4. Ahmad S, Azid NA, Boer JC, et al. (2018) The Key Role of TNF-TNFR2 teractions in the Modulation of Allergic Inflammation: A Review. Front. Immunol; 9:2572.

5. Polukort SH, Rovatti J, Carlson L, et al. (2016) IL-10 Enhances IgE-Mediated Mast Cell Responses and Is Essential for the Development of Experimental Food Allergy in IL-10-Deficient Mice. I Immunol; 15:196(12):4865-76.

6. National Cancer Comprehensive Network (NCCN). 2018. https://www.nccn.org/professionals/physician gls/default.aspx

7. Brożek J, Bousquet J, Agache I, et al. (2017) Allergic Rhinitis and its Impact on Asthma (ARIA) guidelines-2016 revision, Journal of Allergy and Clinical Immunology. 140(4): 950-8.

8. Global Initiative for Asthma (GINA); definition of asthma, introduction, diagnose and management of asthma, https://ginasthma.org/ assessed Jan 2018.

9. Zuberbier T, Aberer W, Asero R, et al. (2018) The EAACI/GA ${ }^{2}$ LEN/EDF/WAO Guideline for the definition, classification, diagnosis and management of urticaria. Allergy; 73:1393-1414. 
10. Bosquet J, Heinzerling L, Bachert C, et al. (2012) Practical guide to skin prick tests in allergy to aeroallergens. Allergy; 67:18-24.

11. Skloot GS. (2015) Tests for assessing asthma in Allergy and Clinical Immunology. Sampson HA ed. Mount Sinai expert guides. 1st edition. Wily Blackwell. P77-81.

12. Gharagozlou $M$, Rastegari $V$, Movahedi $M$, et al. (2005) Total Serum IgE and Skin Tests in Children with Respiratory Allergy Tanaffos; 4(15):27-31.

13. http://www.gentaurpdf.com/pdf/Human\%20IL10\%20ELISA\%20kit.pdf

14. https://www.fn-test.com/content/uploads/ product/manuals/elisa/EH0302.pdf.

15. David A. Freedman. (2009) Statistical Models: Theory and Practice. Cambridge University Press; p. 128.

16. Linabery AM, Jurek AM, Duval S, et al. (2010) The association between atopy and childhood/ adolescent leukemia: a meta-analysis. American journal of epidemiology; 171:749-764.

17. Sherman PW, Holland E, Sherman JS. (2008) Allergies: their role in cancer prevention. $Q$ Rev Biol; 83:339-362.

18. Shadman M, White E, De Roos AJ, et al. (2013) Associations between allergies and risk of hematologic malignancies: results from the VITamins and lifestyle cohort study. Am J Hematol; 88:10501054.

19. Koshiol J, Lam TK, Gridley G, et al. (2011) Racial differences in chronic immune-stimulatory conditions and risk of non-Hodgkin's lymphoma in veterans from the United States. J Clin Oncol; 29:378-785

20. Hjalgrim H, Smedby KE, Rostgaard K, et al. (2007) Infectious mononucleosis, childhood social environment, and risk of Hodgkin lymphoma. Cancer Res; 67:2382-2388.

21. Fabbro-Peray P, Daures JP, Rossi JF. (2001) Environmental risk factors for non-Hodgkin's lymphoma: a population-based case-control study in Languedoc-Roussillon, France. Cancer Causes Control; 12:201-212.

22. Kristinsson SY, Koshiol J, Bjorkholm M, et al. (2010) Immune-related and inflammatory conditions and risk of lymphoplasmacytic lymphoma or Waldenstrom macroglobulinemia. J Natl Cancer Inst; 102:557-567.

23. Soderberg KC, Hagmar L, Schwartzbaum J, et al. (2004) Allergic conditions and risk of hematological malignancies in adults: a cohort study. BMC Public Health; 4:51.
24. Linabery AM, Jurek AM, Duval S, et al. (2010) The association between atopy and childhood/ adolescent leukemia: a meta-analysis. $A m$ J Epidemiol; 171:749- 764

25. Schmiegelow K, Vestergaard T, Nielsen SM, et al. (2008) Etiology of common childhood acute lymphoblastic leukemia: the adrenal hypothesis. Leukemia; 22:2137-2141.

26. Hellstrand K. (2002) Histamine in cancer immunotherapy: a preclinical background. Semin Oncol; 29: 35-40.

27. Perz JB, Ho AD. (2008) Histamine dihydrochloride for the treatment of acute myeloid leukemia, malignant melanoma and renal cell carcinoma. Future Oncol; 4:169-177.

28. Brandes LJ, LaBella FS, Warrington RC. (1991) Increased therapeutic index of antineoplastic drugs in combination with intracellular histamine antagonists. J Nat/ Cancer Inst; 83:1329-1336.

29. Johansen $P$, Weiss $A$, Bünter $A$, et al. (2011) Clemastine causes immune suppression through inhibition of extracellular signal-regulated kinasedependent proinflammatory cytokines. J Allergy Clin Immunol; 128:1286-1294.

30. Döbbeling $U$, Waeckerle-Men $Y$, Zabel $F$, et al. (2013) The antihistamines clemastine and desloratadine inhibit STAT3 and c-Myc activities and induce apoptosis in cutaneous T-cell lymphoma cell lines. Exp Dermatol; 22:119-124.

31. Biggar RJ, Christiansen $M$, Rostgaard $K$, et al. (2009) Immunoglobulin subclass levels in patients with non-Hodgkin lymphoma. Int. J. Cancer; 124:2616-2620.

32. Ellison-Loschmann L, Benavente $\mathrm{Y}$, Douwes J, et al. (2007) Immunoglobulin E levels and risk of lymphoma in a case-control study in Spain. Cancer Epidemiol. Biomarkers Prev; 16, 1492-1498.

33. Hamblin AD, Hamblin TJ. (2008) The immunodeficiency of chronic lymphocytic leukaemia. Br. Med. Bull; 87: 49-62.

34. Maynard CL, Harrington LE, Janowski KM, et al. (2007) Regulatory T cells expressing interleukin 10 develop from Foxp3+ and Foxp3- precursor cells in the absence of interleukin 10. Nature immunology; 8(9):931-941.

35. Mocellin S, Panelli MC, Wang E, et al. (2003) The dual role of IL-10. Trends in immunology; 24(1):3643

36. Dennis KL, Blatner NR, Gounari F, et al. (2013) Current status of interleukin-10 and regulatory $\mathrm{T}$ cells in cancer. Current opinion in oncology; 25(6):637-645. 
37. Vicari AP, Trinchieri G. (2004) Interleukin-10 in viral diseases and cancer: exiting the labyrinth? Immunological reviews; 202:223-236.

38. Visco C, Vassilakopoulos TP, Kliche KO, et al. (2004) Elevated serum levels of IL-10 are associated with inferior progression-free survival in patients with Hodgkin's disease treated with radiotherapy. Leukemia \& Iymphoma. 45(10):2085-2092.

39. Toriyama Y, Miki C, Inoue Y, et al. (2010) Loss of tissue expression of interleukin- 10 promotes the disease progression of colorectal carcinoma. Surgery today; 40(1):46-53.

40. Zhao S, Wu D, Wu P, et al. (2015) Serum IL-10 Predicts Worse Outcome in Cancer Patients: A MetaAnalysis. PLoS ONE; 10 (10): e0139598.

41. Lee HS, Park HW, Song WJ, et al. (2016) TNFalpha enhance Th2 and Th17 immune responses regulating by IL23 during sensitization in asthma model. Cytokine; 79:23-30.

42. Choi JP, Kim YS, Kim OY, et al. (2012) TNF-alpha is a key mediator in the development of Th2 cell response to inhaled allergens induced by a viral PAMP double-stranded RNA. Allergy; 67:1138-1148.

43. Iwasaki M, Saito K, Takemura M, et al. (2003) TNFalpha contributes to the development of allergic rhinitis in mice. J Allergy Clin Immunol. 112:134-140.

44. Ferlay J, Soerjomataram I, Dikshit R, et al. (2014) Cancer incidence and mortality worldwide: sources, methods and major patterns in GLOBOCAN 2012. Int J Cancer; 136(5):E359-86.

45. Sanchez-Correa B, Bergua JM, Pera A, et al. (2013) Cytokine profiles in acute myeloid leukemia patients at diagnosis: survival is inversely correlated with IL-6 and directly correlated with IL-10 levels. Cytokine; 61; 885-891.
46. Tsimberidou AM, Estey E, Wen S, et al. (2008) The prognostic significance of cytokine levels in newly diagnosed acute myeloid leukemia and highrisk myelodysplastic syndromes. Cancer; 113; 16051613.

47.Aguayo A, Kantarjian H, Mansouri T, et al. (2000) Angiogenesis in acute and chronic leukemias and myelodysplastic syndromes. Blood; 96; 2240-2245.

48. Guilloton F, de Thonel A, Jean C, et al. (2005) TNF alpha stimulates NKG2D-mediated lytic activity of acute myeloid leukaemia cells. Leukemia; 19; 22062214.

49. Lebecque S, Dolecek C, Laffer S, et al. (1997) Immunologic characterization of monoclonal antibodies that modulate human IgE binding to the major birch pollen allergen Bet $v 1$. J Allergy Clin Immunol; 99:374-384.

50. Josephs DH, Spicer JF, Karagiannis P, et al (2014) IgE immunotherapy: a novel concept with promise for the treatment of cancer. Monoclonal Antib; 1:5472.

51. Turner MC, Chen Y, Krewski D, et al. (2005) Cancer mortality among US men and women with asthma and hay fever. Am J Epidemiol; 162: 212221.

52. Karagiannis P, Singer J, Hunt J, et al. (2009) Characterization of an engineered trastuzumab IgE antibody and effector cell mechanisms targeting FIER2/neupositive tumour cells. Cancer Immunol Immunother; 58:915-930.

53. Fu SL, Pierre J, Smith-Norowitz TA, et al. (2008) Immunoglobulin $\mathrm{E}$ antibodies from pancreatic cancer patients mediate antibody-dependent cell-mediated cytotoxicity against pancreatic cancer cells. Clin Exp Immunol; 153:401-409. 